\title{
ДЕКАРБОНИЗАЦИЯ, КАК ФАКТОР СМЕНЫ МИРОВОЙ ЭНЕРГЕТИЧЕСКОЙ ПАРАДИГМЫ
}

\author{
(c) 2021 Кация Гурам Джониевич \\ кафедра экономики и управления предприятиями и производственными комплексами \\ Санкт-Петербургский государственный экономический университет \\ магистр экономики, Россия, Санкт-Петербург \\ E-mail: Guram10@mail.ru
}

Основными шагами в определении роли фактора декарбонизации в смене мирового энергетического баланса должны стать исследования рынка, анализ тенденций, связанных с разработкой и применением стратегий декарбонизации в страновом разрезе, анализ перспективных технологий. Целью статьи является краткий обзор выполненных автором исследований.

Ключевые слова. Декарбонизация, энергетическая парадигма, смена, развитие, перспективы.

На сегодняшний день тема декарбонизации занимает лидирующие позиции в формировании глобальной стратегии борьбы с изменением климата. Декарбонизация подразумевает использование низкоуглеродных технологий, которые могут уберечь человечество от глобального потепления. Декарбонизация является основой четвертого глобального энергетического перехода.

Чтобы противостоять угрозе, связанной с глобальным потеплением страны консолидируются и берут на себя жесточайший обязательства в рамках Парижского соглашения, а также сверх этих рамок, берут обязательства по сокращению своего углеродного следа. На сегодняшний день больше 70 стран мира заявило о стремлении к полной углеродной нейтральности, то есть нулевых нетто выбросов парниковых газов в атмосферу к 2050-2060 гг. Для того, чтобы выполнить взятые на себя обязательства, этим странам придется полностью перекроить свою экономическую модель, то есть отказываться от многих привычных и простых в добыче энергоресурсов, сворачивая целые отрасли промышленности, проводить дорогостоящую глубокую модернизацию, придется развивать совершенно новые малоизученные отрасли, например хранение и улавливание углерода. По оценкам международного энергетического агентства к 2050 году эта отрасль должна обеспечивать в два раза большие объемы закачки СО2 под землю, чем в дынный момент добывается нефти. История наблюдений изменения климата происходит быстрее, чем предполагалось. Для стран богатых энергоресурсами, изменение климата происходит быстрее.
Вопрос декарбонизации тесно связан со следующими понятиями, которые также набирают широкую популярность среди мирового сообщества, а именно зеленая энергетика, устойчивое развитие.

Зеленая энергетика - комплекс технологий, основой которого являются возобновляемые источники энергии. Сегодня, подход к вопросу классификации возобновляемых источников энергии остается открытым. Наиболее распространенное понятие включает в себя: солнечную, ветровую, геотермальную генерацию энергии. Данная классификация характерна для развитых стран, таких как страны Европейского Союза, США, а также Япония. В Российской Федерации к возобновляемым источникам энергии часто относят АЭС и ГЭС.

Если говорить о понятии усточивого развития, то стоит упомянуть о 17 целях, которые предполагает данная стратегия. Многие из них так или иначе связаны со снижением выбросов парниковых газов.

На основе понятий, которые указаны выше, складываетя вектор глобального развития, который направлен не только на быстрый экономический рост стран и улучшение жизни нынеживущих жителей земли, но и сохранение и приумножение благ, которые сегодня имеет человечество. Технологические изменения, которые сегодня внедряются во все сектора мировой экономики, влекут за собой полное изменение облика мировой энергетики, иными словами смены мировой энергетической парадигмы.

В данной концепции речь идет не только о вытеснении и сокращении ископаемого топли- 
ва, но и о преобразовании всей модели энергетического рынка. Иначе говоря, применение зеленых технологий влечет за собой развитие целого спектра перспективных направлений. Особняком здесь стоит распределенная генерация, которая активно развивается в развитых странах [5]. На ряду с ней активную поддержку получают проекты, связанные с водородными технологиями.

Как мы знаем, одной из главных проблем развития зелёной энергетики является вопрос долгосрочного хранения и транспортировки электроэнергии, выработанной с помощью возобновляемых источников энергии. Данная проблема может быть решена путём внедрения водородных технологий в цепочку производства, хранения и транспортировки зелёной энергии. В данном случае, важно понимать отличия зелёного водорода, который является наиболее чистым, от аналогов. Производство зеленого водорода требует применения технологии электролиза, которая в свою очередь является очень энергозатратным [4]. То есть, производить энергию непосредственно под производство водорода - экономически нецелесообразно. Может появиться вопрос, в чем же тогда смысл производство зелёного водорода. Ответ на этот вопрос следующий, водородные технологии являются дополнением к системе ветровой и солнечной генерации, а в нашем случае гидроэлектростанций и АЭС. Иными словами, в пиковые часы (утро и вечер) происходит выработка энергии для потребителей, при этом в часы низкой загрузки (день и ночь) они могут производить электричество, которое будет питать электролизер. В данном случае электричество является бесплатным для потребления электролизеров. Наиболее наглядным примером здесь является опыт внедрения водородных технологий Европейским Союзом и Японией, где собственники ветровых установок и солнечных панелей утверждали, что им выгоднее продолжать генерировать невостребованную электроэнергию, чем просто отключить агрегаты. При этом стоит отметить, что в Европейском Союзе доля распределённой генерации с каждым годом растёт [3]. Это делает энергосистему более гибкой. В случае с Российской Федерацией, энергосистема в большей своей части является централизованной. Это означает, что внедрение возобновляемых источников энергии должно начаться в локальных масштабах, а по мере увеличения доли в общем энергетиче- ском балансе, должно увеличиваться внедрение технологий по производству зелёного водорода.

При всей перспективе водородных технологий стоит учесть проблемы, связанные с развитием инфраструктуры. Сегодня водород может быть использован не только в качестве сырья в промышленности, но и в качестве топливного элемента, а также являться тем самым веществом, которое позволит транспортировать определённый объем энергии из одной точки в другую и быть альтернативой грязным в производстве литий-ионным батареям. Исходя из этого, появляются вопросы:

1. Кто может быть потребителем водорода?

2. В чем транспортировать и хранить водород?

Итак, наиболее перспективным потребителем водорода является транспорт. На сегодняшний день, в России существуют альтернативная стратегия которая направлена на развитие природного газа в качестве моторного топлива. Данная стратегия включает в себя программы развития газомоторной инфраструктуры в различных регионах. Стоит отметить, что газомоторная инфраструктура близка к водородной. Именно поэтому существует возможность создания водородных заправочных комплексов на базе метановых заправок, также возможно создание многотопливных заправочных комплексов. Автомобили на водородном топливном элементе активно начали разрабатывать и эксплуатировать в Японии и Европейском Союзе [2].

Если мы говорим о транспортировке и хранении водорода, то стоит отметить, что для транспортировки и хранения требуются ёмкости, схожие по своим характеристикам с емкостями для КПГ. Также при транспортировке возможно использование трубопроводной инфраструктуры.

Европейский Союз принял стратегию развития водородной экономики, которая подразумевает несколько этапов:

1. локальное производство зелёного водорода на базе возобновляемых источников энергии;

2. подключение к электролизёру большего количества ВИЭ, а также перевод автомобилей на водородное топливо;

3. применение в масштабах страны;

4. экспорт и импорт водорода - создание нового энергетического рынка

Синергия перспективных технолгий, а атакже их имплементация с мировой экономикой 
позволят не только сократить антропогенные выбросы парниковых газов, но и улучшить условия жизни современного и будущего поколений.

Перед ключевыми игроками энергетического рынка встает вопрос, правда ли зеленые технологии являются ключем к достижению целей декарбонизации. Некоторые страны и компании приняли экстремальные меры, которые имеют точные сроки по отказу от ископаемых видов топлива. Развитые страны, такие как Франция, Германия, Норвегия, Япония объявили о планах по введению запрета на эксплуатацию автомобилей с двигателями внутреннего сгорания с 2040 года [6]. Это означает замену их на электромобили, как самую чистую альтернативу традиционным автомобилям. Действительно, их эксплуатация являестя наиболее экологичной, однако многие забывают о колоссальном карбоновом следе, который наблюдается во всей производственной цепочке таких автомобилей. Для обеспечения производства используют в основном ископаемое топливо, что ставит под сомнение всю целесообразность их использова- ния. Многие страны настроены более скептично. В России в качестве альтернативы реализуется стратегия развития газа в качестве моторного топлива [1]. Эффект в данном случае действительно серьезный. Помимо сокращения выбросов парниковых газов, сокращаются выбросы тяжелых металлов при эксплуатации автомобилей. До сих пор ведутся споры вокруг приянтия и исполнения мер по декорбонизации между странами. Развитые страны говорят о мерах по декорбонизации при этом умалчивая, что национальные компании переносят свои производства в развивающиеся страны.

Таким образом, можно сделать вывод, что такой фактор, как декарбонизация является одним из ключевых в вопросе смены мировой энергетической парадигмы. Глобальный сдвиг интересов инвесторов, регуляторов и потребителей в сторону декарбонизации привел к тому, что тематики, свзяанные с развитием перспективных углеродонейтральных технологий выходят на передний план общемировой повестки.

\section{Библиографический список}

1. Распоряжение Правительства РФ от 9 июня 2020 г. № 1523-р Об Энергетической стратегии РФ на период до 2035 г. (в действующей редакции).

2. IRENA, (forthcoming). Demand side flexibility for the energy transition - Analytical Brief [Электронный ресурс] // - Режим доступа: https://www.irena.org/, свободный.- Загл. с экрана. Яз. англ.

3. IEA, 2004. Prospects for CO2 Capture and Storage, Energy Technology Analysis [Электронный ресурс] // - Режим доступа: https://www.iea.org/, свободный.- Загл. с экрана. Яз. англ.

4. IRENA, 2018b. Power System Flexibility for the Energy Transition. Part I: Overview for Policy Мakers [Электронный ресурс] // - Режим доступа: https://www.irena.org/, свободный.- Загл. с экрана. Яз. англ.

5. IRENA, 2019. A RENEWABLE ENERGY PERSPECTIVE [Электронный ресурс] // - Режим доступа: https://www. irena.org/, свободный - Загл. с экрана. Яз. англ.

6. National Renewable Energy Laboratory, 2014. Hydrogen Station Compression and Dispensing Technical Status and Costs [Электронный ресурс] // - Режим доступа: https://www.irena.org/, свободный - Загл. с экрана. Яз. англ.

7. Мировая энергетическая статистика, [Электронный ресурс] // - Режим доступа: https://yearbook.enerdata. $\mathrm{ru} /$, свободный.- Загл. с экрана. Яз. рус.

8. World Energy Council, 2021. World Energy Issues Monitor [Электронный ресурс] // - Режим доступа: https:// www.worldenergy.org, свободный - Загл. с экрана. Яз. англ. 